\title{
A Case of Refractory Idiopathic Tumoral Calcinosis Cutis
}

\author{
Siddiqui $\mathbf{S}^{1}$, Ahmed $\mathbf{G}^{2}$, Qaisar $\mathrm{H}^{3}$, Wahid $\mathrm{Z}^{4}$, Talat $\mathrm{H}^{5}$
}

${ }^{1}$ Post Graduate Trainee, Department of Dermatology, Civil Hospital, Karachi, Pakistan, ${ }^{2}$ Research Assistant, Department of Medicine, Civil Hospital, Karachi, Pakistan, ${ }^{3}$ Medical Student, Dow University of Health Sciences, Karachi, Pakistan, ${ }^{4}$ Professor \&Head of Dermatology Department, Civil Hospital, Karachi, Pakistan, ${ }^{5}$ Assistant Professor, Department of Dermatology,Civil Hospital, Karachi, Pakistan.

\begin{abstract}
A case of idiopathic tumoral calcinosis cutis in a normocalcemic patient. The lesions were localized to multiple large and small joints throughout the body and confirmed on biopsy. The lesions are refractory to intralesional steroids, aluminum hydroxide and diltiazem after 5 months. The patient is being considered for surgical intervention for large lesions while he will be further tried on dialitiazem for the smaller ones.
\end{abstract}

Key words: Calcinosis Cutis, Tumoral, Refractory, Diltiazem

\section{Introduction}

W e present you a case of tumoral calcinosis cutis, cause of which still remains unknown and generally effects the larger joints. ${ }^{1}$ It is a disease of exclusion and tagged idiopathic after ruling out kidney disorders, Vitamin D excess, milk alkali syndrome, paraneoplastic syndrome, sarcoidosis and trauma ${ }^{2-3}$. In most cases these lesions gradually appear as firm, non-tender, whitish or yellowish papules, plaques or nodules on the surface of the skin. They can be solitary but multiple lesions are more common. Tumoral calcinosis is frequently localized to the large joints ${ }^{4}$ including hips, shoulder, elbows, feet and buttocks ${ }^{1}$ and less commonly to the hand and digits. ${ }^{5}$

\section{Case Report}

A 27 years old male with no known co-morbids came to us with complaints of multiple small elevations over joints and buttocks for 10-12 years. There was no history of trauma or parenteral therapy or family history of similar lesions. It first appeared as a painless hard whitish rounded elevation of $1-2 \mathrm{~mm}$ in diameter and progressively involved other areas of his body (specifically small and large joints, shoulder blades and buttocks) within 6 months. These lesions ruptured releasing whitish material and was associated with

Address for correspondence

Hira Qaiser

Dow University of Health Sciences,

Karachi, Pakistan.

E-mail: hayaqaisar@hotmail.com

Contact: \# +923363937697 restriction of movement over involved joint. There were no other rheumatological or dermatological associations.

On examination; the patient was vitally stable (BP: $120 / 80 \mathrm{~mm}$ of $\mathrm{Hg}$, Temperature: $37^{\circ} \mathrm{C}$, Pulse: 80 bpm, Respiratory rate: 18 breaths/ min). His systemic examination was insignificant and on cutaneous examination, multiple whitish, hard, papulonodular lesions were seen on his fingers, elbows, knees, buttocks and shoulder blade as shown in Figure 1 and 2 along with a fixed flexion contracture of the right index finger.

Lab investigations showed a raised SGPT (50; reference range : 1-30U/L), SGOT (45; reference range: 1-40U/L), GGT (48; reference range 5-27 U/L),CPK (209; reference range: 46-171 IU/L) positive ANA, negative RA factor, negative anti $C C P$, negative anti dsDNA, negative ENA profile and very low serum vitamin D3 (8.32; reference range $>30$ ).

Differential diagnosis of this case included Tuberous Xanthoma, Perforating Disorder, Granuloma Annulare (nodular variety), Rheumatoid Nodule, Systemic Lupus Erythematosus and Gout. These were excluded on the basis of history, clinical examination and laboratory findings in our patient.

Electromyography was ordered which showed normal study. X-ray films displayed multiple calcific nodules in soft tissue of both elbow joints, both hip joints and both knees, no bone or joint involvement was noticed. Xray are shown through Figures 3 A, B, C and D. 


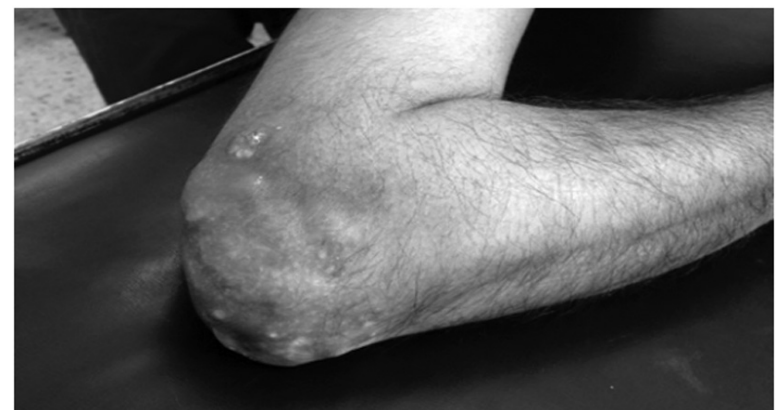

Figure 1A: Elbow

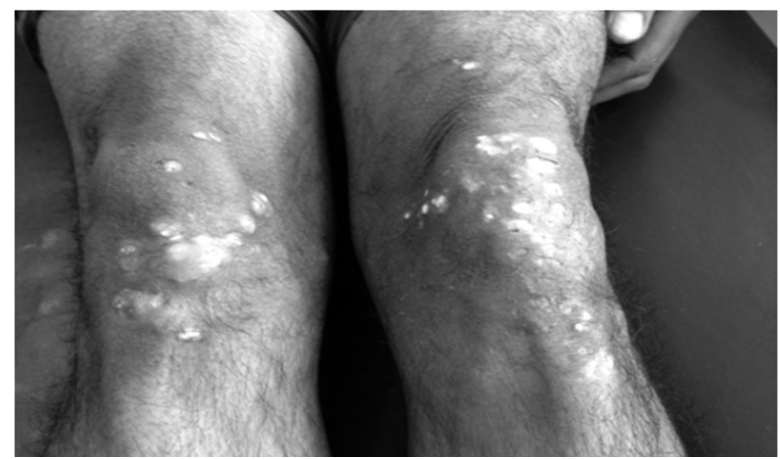

Figure 1C: Knees

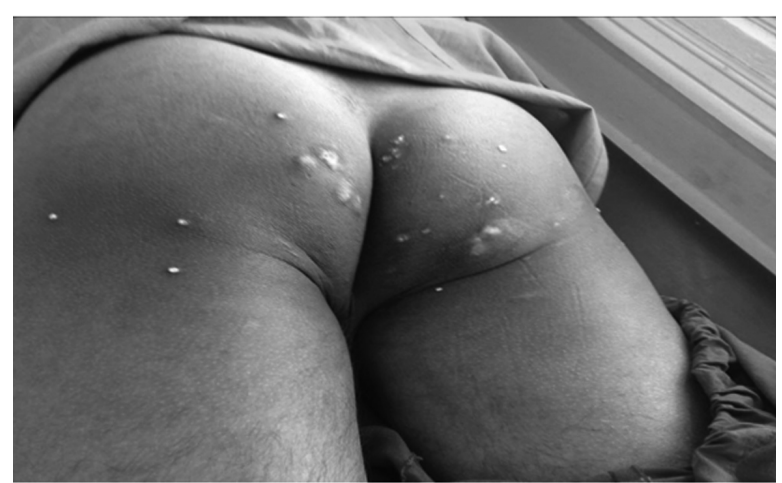

Figure 2: Buttocks

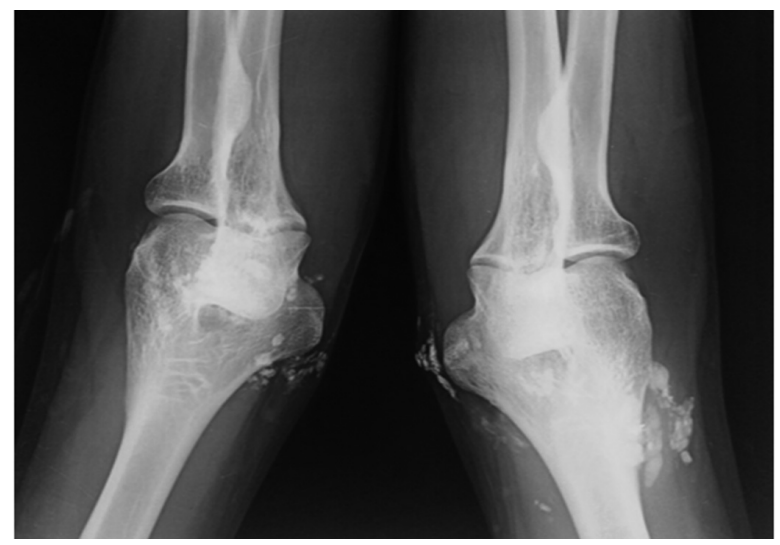

Figure 3B: Xray Elbows

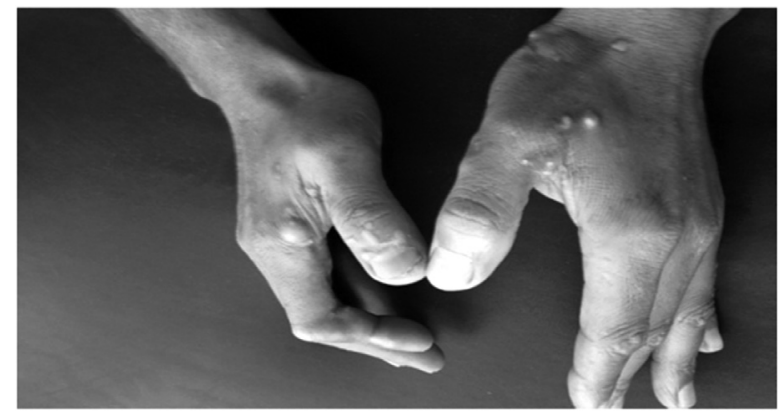

Figure 1B: Hands

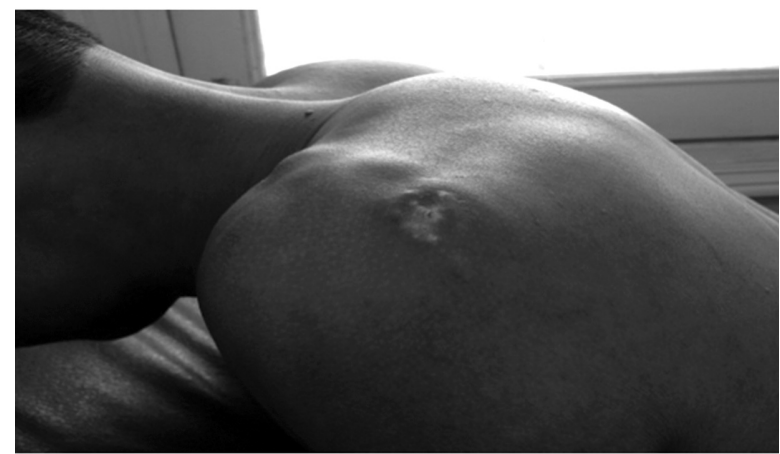

Figure 1D: Shoulder

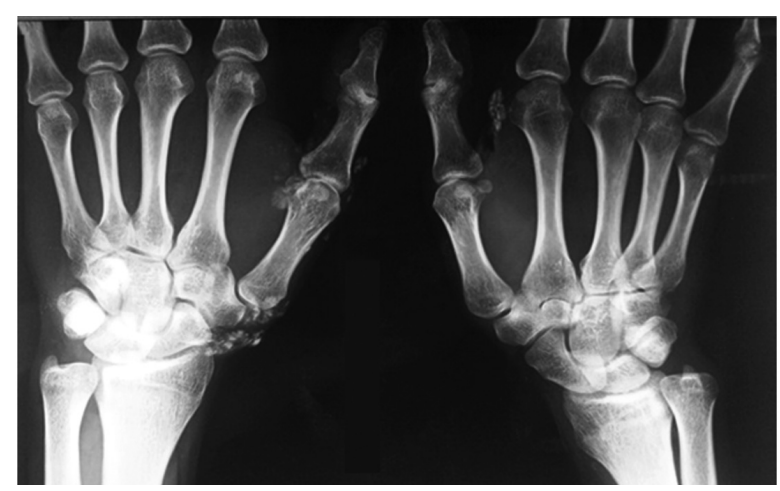

Figure 3A: Xray Hands

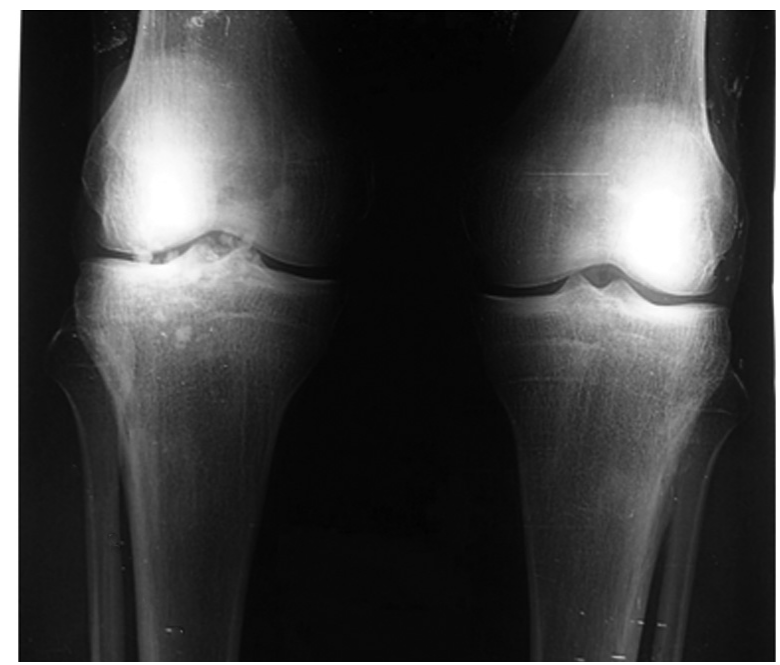

Figure 3C: Xray Knee Joint 


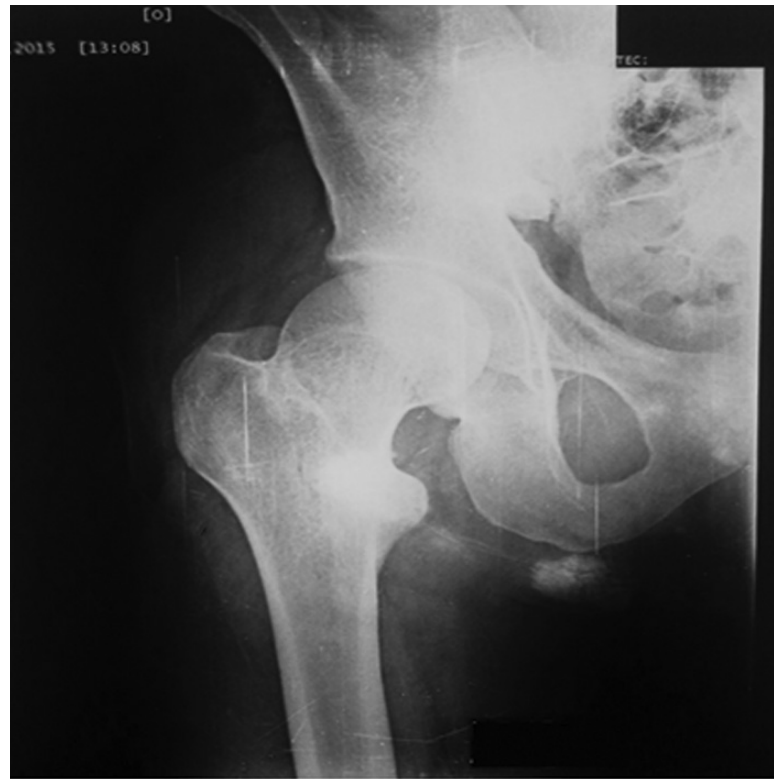

Figure 3D: Xray Right Hip Joint

Skin biopsy was done and histopathology showed fragments of skin having orthokeratoses, underlying dermis showed variable sized foci of calcificationssigns consistent with Calcinosis Cutis as shown in Figure 4.

The final pathological diagnosis was idiopathic tumoral calcinosis cutis. He was given intralesional corticosteroids and aluminum hydroxide but it showed no improvement, he was discharged with Diltiazem and followed up for 5 months, his lesions showed no marked improvement over time. He is being considered for surgical intervention for larger lesions while the smaller ones will be further tried on diltiazem.

\section{Discussion}

Idiopathic tumoral calcinosis cutis is rare condition characterized by calcium deposition in skin and subcutaneous tissues. In all cases of calcinosis cutis, insoluble compounds of calcium are deposited within the skin due to local and/or systemic factors. These calcium salts consist primarily of hydroxyapatite crystals or amorphous calcium phosphate. It commonly affects blacks with no apparent gender predilection. ${ }^{6,7}$

From the pathogenesis point of view, the condition is classified as metastatic, dystrophic, iatrogenic, idiopathic and calciphylaxis. Dystrophic variant has normal serum calcium and phosphate values with history of trauma whereas metastatic variant shows abnormal ranges of calcium and phosphate. In latrogenic subtype calcium salts deposit in the skin as a side effect of medical intervention for

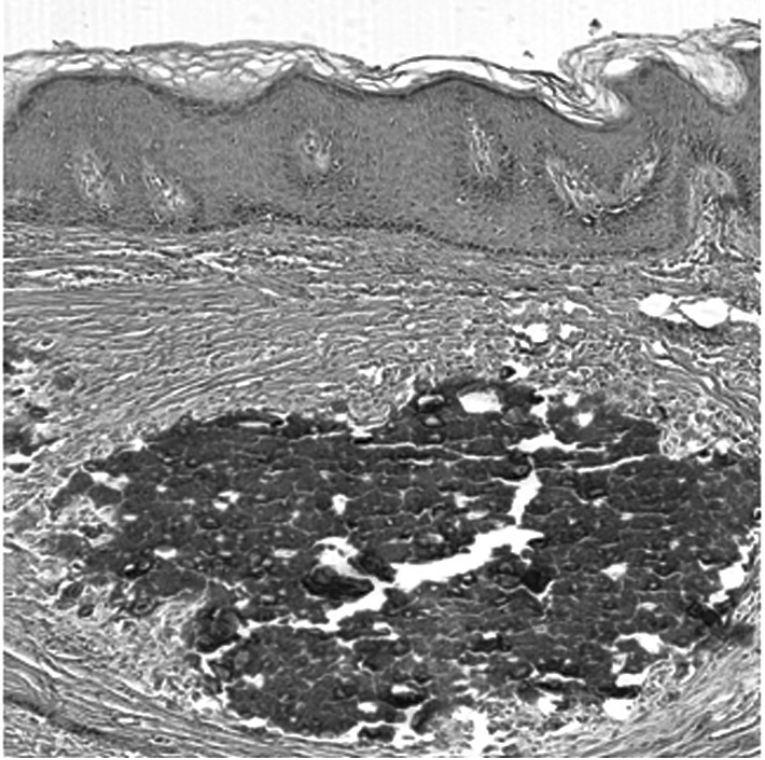

Figure 4: Skin biopsy

other disease processes. Calciphylaxis is associated with small vessel calcification in the dermis and subcutaneous fat causing infarction and there may be associated hyperparathyroidism and disturbances in the phosphate and calcium metabolism, or as in this case idiopathic calcinosis cutis occurs in the absence of any underlying tissue damage or metabolic condition. Abnormality in gamma carboxy glutamic acid metabolism has been postulated in the pathogenesis of Idiopathic Calcinosis Cutis, which is normally found in bones and tissues. ${ }^{8}$

Idiopathic calcinosis is further divided into 4 types. Calcinosis Universalis which diffusely involves muscles and soft tissues, Calcinosis circumscripta characterized by localized lesions, solitary calcinosis and tumoral calcinosis which is characterized by lesions around large joints.

Our patient presented with multiple asymptomatic nodules which developed gradually, which is in accordance with the literature. ${ }^{9}$ Lesions may become painful, limit mobility of an adjacent joint, or compress adjacent neural structures. Ulceration and secondary infection may occur. Vascular calcification may result in ischemia and necrosis of the affected organ. Healthy adolescents similar to this case can present with large calcified masses within subcutaneous tissue or muscles near large joints, ${ }^{[10]}$ without involvement of internal organs.

Radiographically, tumoral calcinosis lesions appear as rounded, dense periarticular opacities. Masses may be small and solid or large and cystic on computed 
tomography. Despite a large amount of calcification, masses usually display high signal intensity on T2weighted MRI images. ${ }^{3}$ Renal function tests and levels of serum calcium, parathyroid hormone, alkaline phosphatase, inorganic phosphate and vitamin D are normal in tumoral calcinosis. Sometimes the level of the latter two may be slightly elevated. ${ }^{6,11}$ Contrary to above our case had low serum vitamin $D$ levels and also deranged liver enzymes levels.

Biopsy is diagnostic in many cases. Histopathology classically shows calcium deposition with surrounding foreign-body reaction, ${ }^{12}$ which was also seen in this case along with orthokeratoses.

Intralesional corticosteroids, diltiazem, colchicine,

\section{References}

1. Ovali G, Tarhan S, Serter S, Bayindir P, Okcu $G$, Demireli $P$, et al. A rare disorder: idiopathic tumoral calcinosis. Clin Rheumatol 2007; 26(7): 1142-4. http://dx.doi.org/10.1007/s10067006-0269-3.

2. Chaabane $S$, Chelli-Bouaziz $M$, Jelassi $H$, Mrad K, Smida M, Ladeb MF. Idiopathic tumoral calcinosis. Acta Orthop Beig 2008; 74(6): 83745.

3. Olsen KM, Chew FS. Tumoral calcinosis: pearls, polemics, and alternative possibilities. Radiographics 2006; 26: 871-85. http://dx.doi. org/10.1148/rg.263055099

4. Alam A, Ram S, Manrai K, Bhardwaj R. Tumoral calcinosis. Med J Armed Forces India 2007; 63: 180-1. http://dx.doi.org/10.1016/S03771237(07)80072-4

5. Kim HS, Suh JS, Kim YH, Park SH. Tumoral calcinosis of the hand: three unusual cases with painful swelling of small joints. Arch Pathol Lab Med 2006; 130: 548-51. [PubMed]

6. Bishop AF, Destouet JM, Murphy WA, Gilula LA. Tumoral calcinosis: case report and review. Skeletal Radiology 1982; 8: 269-274. http:// dx.doi.org/10.1007/BF02219621.

7. Viegas SF, Evans EB, Calhoun J, Eng M, Goodwiller SE. Tumor calcinosis: a case report and review of the literature. J Hand Surg Am aluminium hydroxide, and warfarin are known to have beneficial effect in this condition. ${ }^{13}$ Failure of medical treatment can be followed by surgical excision. ${ }^{14}$ Other indications for surgical treatment include painful masses, recurrent infection, ulcerations, functional impairment and cosmetic concerns. ${ }^{15}$ The patient didn't respond much to the medications and surgery was considered but was ruled out due to widespread involvement of body with lesions.

Calcinosis cutis generally is a benign process. When present, morbidity is related to the size and location of the calcification. Spontaneous regression of the mass of tumoral calcinosis has never been reported. The prognosis is good particularly in the absence of secondary infection.
1985; 10: 744-748. http://dx.doi.org/10.1016/ S0363-5023(85)80225-2.

8. Jatana SK, Negi V, Das S. A case of idiopathic calcinosis cutis. Medical Journal, Armed Forces India 2012; 68(4): 383-385. http:// dx.doi:10.1016/j.mjafi.2012.07.006.

9. McClatchie S, Bremner A. Tumoral calcinosisan unrecognised disease. BMJ 1969; 1: 153-155. http://dx.doi.org/10.1136/bmj.1.5637.142-a

10. Walsh JS, Fairley JA. Calcifying disorders of the skin. J Am Acad Dermatol 1995; 33: 693-706. http://dx.doi.org/10.1016/01909622(95)91803-5.

11. Rodriguez-Peralto $\mathrm{JL}$, $L$ opez-Barea $F$, Torres $A$, e $t$ al. Tumoral calcinosis in two infants. Clin Orthop Relat Res 1989; 242: 272 - 6.

12. Maize J, Metcalf. Metabolic Diseases of the skin. In: Elder D(editor). Lever's Histopathology of the skin. 8th edn Philadelphia: LippincottRaven; 1997. p. 379-82.

13. Touart DM, Sau P. Cutaneous deposition diseases. Part II. J Am Acad Dermatol 1998; 39: 527-44. http://dx.doi.org/10.1016/SO1909622(98)70001-5

14. Smit GG, Schmaman A. Tumoral calcinosis. J Bone Joint Surg Br 1967; 49: 698-703.

15. Lipskeir $E$, Weizenbluth $M$. Calcinosis circumscripta: Indications for surgery. Bull Hosp Jt Dis Orthop Inst 1989; 49: 75-84. [PubMed] 